\section{AGROTÓXICOS NO ENSINO DE QUÍMICA: PROPOSTA CONTEXTUALIZADA ATRAVÉS DE UM JOGO DIDÁTICO}

\author{
Agrochemicals in Chemistry education: contextualized proposal through a didactic activity \\ Agrotóxicos en la enseñanza de química: propuesta contextualizada a través de una actividad \\ didáctica
}

\section{Resumo}

O presente texto apresenta resultados de uma pesquisa realizada com alunos da terceira série do Ensino Médio, a partir da aplicação de uma sequência didática contextualizada sobre Agrotóxicos, na qual foram discutidos conceitos como: revolução verde, semente crioula, controle biológico, produção orgânica, toxidade e conceitos da Química, por meio da temática "agrotóxicos". Focalizaram-se as discussões no último encontro, em que foi realizado um jogo didático denominado "Trilha dos Agrotóxicos" para discutir a temática e retomar alguns pontos trabalhados anteriormente. Aplicou-se um questionário de perguntas abertas para verificar se o jogo didático contribuiu para a aprendizagem dos estudantes. Os dados foram examinados por intermédio da Análise de conteúdo, em que a maioria relatou que as atividades diversificadas promoveram melhor compreensão do conteúdo, tornando a aula mais atraente e propiciando um entendimento menos abstrato da Química, visto que os conceitos foram relacionados ao contexto.

Palavras-chave: Ensino de Química; agrotóxicos; jogo didático.

\begin{abstract}
This paper presents results of a research carried out with students of the third grade of High School, from the application of a didactic sequence contextualized on Agrochemicals, in which were discussed concepts such as: green revolution, Creole seed, biological control, organic production, toxicity and concepts of Chemistry, through the theme of "pesticides". The discussions were focused on the last class, in which a didactic game called "Agrochemical Trail" was held to discuss the theme and to return to some previously worked points. An open-ended questionnaire was applied to verify if the didactic game contributed to student learning. The data were examined through Content Analysis, in which most reported that the diversified activities promoted a better understanding of the content, making the class more attractive and providing a less abstract understanding of Chemistry, once the concepts were related to the context.
\end{abstract}

Keywords: Chemistry Teaching; pesticides; didactic game.

\section{Resumen}

El presente texto enseña resultas acerca de una investigación realizada con alumnos del tercer grado del Encino Secundaria por medio de la aplicación de una secuencia didáctica contextualizada sobre Agrotóxicos, en la cual fueron debatidos conceptos como: revolución verde, semilla criolla, control biológico, producción orgánica, toxicidad y conceptos de la Química por medio de la temática agrotóxicos. Se enfocó las discusiones en el ultimo encuentro, en que fue realizado un juguete didáctico nombrado "Pista de los Agrotóxicos" para discutir la temática y retomar algunos puntos trabajados anteriormente. Se aplicó un cuestionario de preguntas abiertas para checar si el juguete contribuyó para el aprendizaje de los estudiantes. Los datos fueron analizados por la Análisis de contenido, en que la mayoría relató que las actividades diversificadas promovieron mejor comprensión de contenido, tornando la clase más atractiva y promoviendo un entendimiento menos abstracto de la Química, ya que los conceptos fueron relacionados con el contexto.

Palabras clave: Enseñanza de Química; agrotóxicos, juguete didáctico.

\section{AUTORES:}

LAURA FREIRE MELLO'

ORCID 0000-0001-6329-6839

${ }^{1}$ Colégio Estadual

Cândida Corina Taborda

Alves

ERIL MEDEIROS DA FONSECA ${ }^{2}$

ORCID 0000-0001-9529-2357

${ }^{2}$ Universidade Federal do Pampa (UNIPAMPA)

LEANDRO DUSO 3

ORCID 0000-0002-2605-0829

3 Universidade Federal do Pampa (UNIPAMPA)

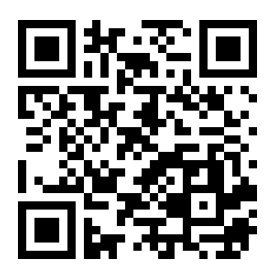

Para citar este artigo:

MELLO, L. F.; FONSECA, E. M.; DUSO, L. Agrotóxicos no ensino de química: proposta contextualizada através de um jogo didático. Revista Eletrônica Ludus Scientiae, Foz do Iguaçu, v. 02, n. 01, p. 76-90, jan./jun., 2018. 


\section{INTRODUÇÃO}

Os modelos de ensino atuais parecem priorizar um currículo pautado em uma abordagem conceitual, em que a organização é estruturada com base nos conceitos científicos, com os quais se selecionam os conteúdos a serem transmitidos (DELIZOICOV; ANGOTTI; PERNAMBUCO, 2011). Nesse sentido, as Diretrizes Curriculares Nacionais (BRASIL, 2010) apontam para a importância de uma educação de qualidade, que respeite e valorize a diversidade humana, contribuindo, assim, com a construção de uma sociedade cada vez mais justa e solidária.

No cenário do Ensino Médio, especificamente na Química Orgânica, tais dificuldades não são diferentes, já que a forma com que os conceitos são abordados limita-se às estruturas trazidas pelos livros didáticos (DELIZOICOV; ANGOTTI; PERNAMBUCO, 2011), dando ênfase a um currículo centrado em questões conceituais, não valorando as contextualizações dos sistemas de ensino.

Delizoicov, Angotti e Pernambuco (2011) mencionam que esta estrutura curricular é, por vezes, influenciada por um currículo pré-estipulado, por isso defendem que é necessário um trabalho em sala de aula que seja estruturado a partir de temática, cujo estudo dos conceitos científicos é subordinado à discussão de uma situação-limite vivenciada pelos alunos e/ou comunidade.

Diante do exposto, apresenta-se, neste trabalho, uma intervenção realizada no município de Dom Pedrito, Rio Grande do Sul, sobre a temática "agrotóxicos". Os sujeitos foco do estudo foram trinta e cinco (35) estudantes de Ensino Médio de uma escola localizada na área urbana ${ }^{1}$.

O município de Dom Pedrito caracteriza-se por uma grande extensão territorial no estado que, na maior parte, é constituído pela produção de pecuária e agricultura de monocultura (arroz e soja). A fronteira com o Uruguai facilita a entrada de agrotóxicos proibidos, favorecendo a sua utilização irregular. A falta de fiscalização por órgãos competentes com assiduidade propicia essa desvantagem à população, a qual sofre as consequências que a utilização desenfreada e o mau uso causam.

A utilização indevida desses produtos afeta diretamente os pequenos produtores, que são vítimas, principalmente, da pulverização aérea nas lavouras vizinhas. Como a maior parte do veneno pulverizado é levada com o vento, acaba atingindo a produção orgânica dos assentados e mananciais de água da região, e muitas vezes as grandes corporações não querem realizar esta análise mais criteriosa devido aos interesses econômicos (DOM PEDRITO, 2016).

Em maio do ano de 2016 foi realizada uma audiência pública no município solicitando à Comissão de Saúde e Meio Ambiente que realizasse um debate sobre os problemas que ocorrem na região, devido ao uso indiscriminado de agrotóxicos nas lavouras de arroz e soja. Foram citados inúmeros problemas de saúde que decorrem diretamente do uso desses produtos, como depressão, dor de cabeça, grande incidência de câncer na região, problemas respiratórios, entre outros (DOM PEDRITO, 2016).

Nesse sentido, acredita-se que o papel da escola é trazer tais debates para dentro das salas de aula. Os componentes das Ciências da Natureza, bem como as demais áreas de conhecimento, como a Química, possibilitam promover discussões, auxiliando os estudantes à compreensão de temas como a incidência do agrotóxico, que é presente no cotidiano de todos na realidade do município.

Por isso, torna-se importante a elaboração de estratégias didáticas nas quais os estudantes estabeleçam relações entre o conhecimento escolar e o contexto no qual está inserido, para que possam se posicionar, suscitando uma tomada de decisão e uma ação socialmente significativa, com a

\footnotetext{
${ }^{1}$ Vale ressaltar que o público-alvo, mesmo vinculado à área urbana, também se caracteriza por estudantes oriundos do contexto do campo, pois a escola atende estudantes desta realidade, já que, não havendo possibilidade de dar continuidade aos estudos, estes se deslocam para a cidade.
} 
finalidade de resolver situações-problema, em consonância com as suas condições intelectuais, emocionais e contextuais.

Diante do exposto, o presente trabalho buscou investigar as potencialidades e as limitações da aplicação de um jogo didático sobre a temática "agrotóxicos", como estratégia de aprendizagem para estudantes de terceira série de uma escola pública estadual de Ensino Médio no ensino de Química, no município de Dom Pedrito.

\section{DISCUSSÃO TEÓRICA}

Primeiramente, apresentamos algumas aproximações realizadas entre o Ensino de Química e a temática "agrotóxicos" e, em seguida, a sistematização dessas questões, pela abordagem teóricoprática de um jogo didático no Ensino de Química.

\section{O Ensino de Química e os agrotóxicos}

Sabe-se que as Ciências Naturais, bem como a Química, estão presentes diariamente na vida dos sujeitos. E necessita-se, cada vez mais, dos conhecimentos científicos para se progredir e sobreviver de acordo com as mudanças frequentes.

Dessa forma, o processo de ensino e aprendizagem das Ciências Naturais deve propor-se a preparar o estudante para uma atitude positiva em relação às mudanças, levando-o a pensar de forma reflexiva, para saber valorizar o ambiente que o cerca e capacitando-o a tomar decisões mais acertadas para com os semelhantes e com a natureza (FERREIRA, 2013).

Segundo os Parâmetros Curriculares Nacionais da área de Ciências Naturais (BRASIL, 1997, p. 21-22), deve-se trabalhar a Ciência como uma elaboração humana, pois seus

[...] conceitos e procedimentos contribuem para o questionamento do que se vê e se ouve, para interpretar os fenômenos da natureza, para compreender como a sociedade nela intervém utilizando seus recursos e criando um novo meio social e tecnológico. É necessário favorecer o desenvolvimento de postura reflexiva e investigativa, de nãoaceitação, a priori, de ideias e informações, assim como a percepção dos limites das explicações, inclusive dos modelos científicos, colaborando para a construção da autonomia de pensamento e de ação.

A contextualização apresenta-se como um modo de ensinar conceitos das Ciências ligados à vivência dos alunos, seja ela pensada como recurso pedagógico ou como princípio norteador do processo de ensino. Este último caracteriza-se pelas relações estabelecidas entre o que o aluno sabe sobre o tema a ser estudado e os conteúdos específicos que servem de explicações e entendimento desses, utilizando-se da estratégia de conhecer as ideias prévias do aluno sobre a abordagem e os conteúdos em estudo (SILVA, 2007).

Os estudos dentro da área da Química podem contribuir para a melhoria do bem-estar de vida das pessoas, ao mesmo tempo em que o uso indevido de suas aplicações pode produzir muitos efeitos negativos (SILVA, 2007). No cotidiano, existem situações em que a Química Orgânica está envolvida e, com base nessa constatação, devemos pensar: Por que os alunos têm tanta dificuldade em aprender algo que está inserido em suas vidas?

Nascimento, Ricarte e Ribeiro (2007, p. o1) mencionam que:

[...] na escola vivemos um paradoxo, pois o ensino de Química Orgânica geralmente possui uma abordagem desconectada do cotidiano do aluno, extremamente teórica. O ensino de Química Orgânica nas escolas deve ser trabalhado de forma mais dinâmica e contextualizada, tendo como objetivo despertar o interesse do aluno 
através da correlação entre os conteúdos abordados na disciplina, seja de cunho teórico ou prático.

Fica evidente a necessária renovação nos aspectos teóricos, metodológicos e motivacionais quando do Ensino da Química Orgânica.

Temas de grande relevância, e que estão no dia a dia das pessoas, são banidos do contexto escolar, o que causa uma fragilidade dos sistemas de ensino, pois aquilo que não se conhece, não pode ser debatido, refletido e entendido. Dessa forma, nas aulas de Química deve-se abordar, não apenas conteúdos químicos como funções orgânicas, mas possibilitar uma abordagem contextualizada, para que questões de cunho social, político, econômico, cultural, científico e tecnológico também sejam discutidas (SILVA, 2007).

Santos e Mortimer (2002, p. 12) destacam que o estudo a partir de temas "[...] permite a introdução de problemas sociais a serem discutidos pelos alunos, propiciando o desenvolvimento da capacidade de tomada de decisão". No entanto, Cavalcanti (2010) considera que as relações estabelecidas entre conteúdo escolar e cotidiano dos estudantes configuram certa dificuldade, e os agrotóxicos como tema possibilitam estabelecer vínculos entre a realidade ambiental, sociopolítica e os conhecimentos escolares.

Nessa perspectiva, ensina-se Química para que o cidadão possa interagir melhor com o mundo e esteja preparado para a vida, para o trabalho e para o lazer (CHASSOT, 1990). Braibante e Zappe (2012) mencionam que uma forma de articular esses aspectos e contextualizar os conteúdos de Química do Ensino Médio é a temática "agrotóxicos", pois podem ser utilizadas diversas estratégias metodológicas.

Destacam-se algumas relações possíveis do conteúdo programático de Química do Ensino Médio com a temática "agrotóxicos", descritas por Braibante e Zappe (2012), das quais: tabela periódica dos elementos químicos, reações orgânicas, soluções, equilíbrio químico, reações químicas, soluções, solubilidade e o pH dos agrotóxicos; estes últimos são dois conceitos importantes, pois influenciam de modo direto a constância dos agrotóxicos no meio ambiente.

Em relação aos agrotóxicos, caracterizam-se como um dos principais insumos agroquímicos utilizados na agricultura. De acordo com o Decreto 4.074/2002, que dispõe sobre a regulamentação dos agrotóxicos no Brasil, estes são agentes de processos físicos, químicos ou biológicos para o uso no cultivo, armazenamento e beneficiamento de produtos agrícolas e, para alterar a composição da flora e fauna, a fim de preservá-las de ações de seres vivos, são considerados nocivos. O seu uso iniciou-se no século XX, em período pós-guerra, momento em que a indústria química, vinculada à fabricação de veneno, percebeu na agricultura um novo mercado para produção (FONSECA; DUSO; HOFFMANN, 2017).

Assim, a tomada de consciência sobre as implicações da utilização dos agrotóxicos e sua relação com conceitos de Química ensinados na escola é muito importante, principalmente para aqueles estudantes de regiões agrícolas, que convivem diariamente com esse tipo de produto, proporcionando a aproximação do Ensino de Química com a realidade que os cerca (BRAIBANTE; ZAPPE, 2012).

\section{Os Jogos didáticos no processo de aprendizagem}

Segundo Soares, Okumura e Cavalheiro (2003), a aplicação de jogos didáticos em sala de aula é uma estratégia que desperta o interesse, devido ao desafio que ele propõe ao aluno. O estudante, por sua vez, é desafiado na busca por satisfação à superação de seu obstáculo, pois o interesse precede a assimilação. 
O desenvolvimento de jogos didáticos no Ensino de Ciências pode minimizar as dificuldades enfrentadas pelos alunos, no estudo de conteúdos considerados abstratos. Segundo Antunes (2003, p. 05), “o jogo é o mais eficiente meio estimulador das inteligências, permitindo que o indivíduo realize tudo que deseja. Quando joga, passa a viver quem quer ser, organiza o que quer organizar, e decide sem limitações".

De acordo com as Orientações Curriculares para o Ensino Médio (BRASIL, 2006, p. 28),

o jogo oferece o estímulo e o ambiente propícios que favorecem o desenvolvimento espontâneo e criativo dos alunos e permite ao professor ampliar seu conhecimento de técnicas ativas de ensino, desenvolver capacidades pessoais e profissionais para estimular nos alunos a capacidade de comunicação e expressão, mostrando-lhes uma nova maneira, lúdica, prazerosa e participativa de relacionar-se com o conteúdo escolar, levando a uma maior apropriação dos conhecimentos envolvidos.

Nesse sentido, os jogos didáticos são uma alternativa viável e interessante para aprimorar as relações entre professor - aluno - conhecimento. Segundo Silveira (1998, p. 02),

[...] os jogos podem ser empregados em uma variedade de propósitos dentro do contexto de aprendizado. Um dos usos básicos e muito importantes é a possibilidade de construir-se a autoconfiança. Outro é o incremento da motivação. Sendo um método eficaz que possibilita uma prática significativa daquilo que está sendo aprendido. Até mesmo o mais simplório dos jogos pode ser empregado para proporcionar informações factuais e praticar habilidades, conferindo destreza e competência.

Os jogos didáticos devem conciliar a liberdade característica dos jogos com a orientação própria dos processos educativos, por isso algumas pessoas acreditam que nesse ponto haja uma contradição, ou seja, a educação é tida como uma atividade séria e controlada, enquanto que jogar lembra diversão ou simplesmente brincar. Entretanto, a validade de tarefas deste tipo, como instrumento que promova aprendizagem, deve considerar que jogos, no ensino, são atividades mediadas pelo professor, tornando-se ocupações sérias e comprometidas com a aprendizagem. Isso não significa dizer que o jogo no ensino perde o seu caráter lúdico e a sua liberdade característica (CUNHA, 2012).

É possível encontrar na literatura especializada em Ensino de Ciências uma infinidade de potencialidades atribuídas ao uso de jogos no ensino: "Enquanto joga o aluno desenvolve a iniciativa, a imaginação, o raciocínio, a memória, a atenção, a curiosidade e o interesse, concentrando-se por longo tempo em uma atividade" (FORTUNA, 2003, p. 16). Para Kishimoto (1996), o jogo não é o fim, mas o eixo que conduz a um conteúdo específico, resultando em um empréstimo da ação lúdica para a compreensão de informações.

Por aliar os aspectos lúdicos aos cognitivos, entendemos que o jogo é uma importante estratégia para o ensino e a aprendizagem de conceitos abstratos e complexos, favorecendo a motivação interna, o raciocínio, a argumentação, a interação entre alunos e entre professores e alunos (CAMPOS; BORTOLOTO; FELICIO, 2003, p. 41).

De modo geral, os jogos didáticos são, para os estudantes, atividades mais significativas para a aprendizagem escolar do que os costumeiros exercícios. Os jogos trazem situações similares, porém mais simples, do que as situações reais que os alunos encontrarão (FERREIRA, 1998).

Cabe destacar que a simples implementação da utilização dos jogos didáticos não garante a aprendizagem. Para os jogos atingirem seu real potencial didático como recurso na sala de aula, especialmente, eles não devem ser apenas "lúdicos", mas também "educativos". 
A utilização dos jogos didáticos nas aulas de Ciências embasa-se nos ideais de Cunha (2012, p. 5), que menciona que "os professores podem utilizar jogos didáticos como auxiliares na construção dos conhecimentos em qualquer área de ensino", utilizando-se dessas ferramentas para tornar o aprendizado mais dinâmico, atrativo e prazeroso. Acrescenta-se a isso o auxílio do caráter lúdico no desenvolvimento da cooperação, da socialização e das relações afetivas, além da possibilidade de utilizar jogos didáticos, de modo a auxiliar os alunos (PEDROZO, 2009).

A proposta de trabalhar com o lúdico visa a uma ação de suporte para que a aprendizagem ocorra de forma efetiva e eficaz, mas que também não abra mão de ser descontraída e prazerosa. Esse argumento reverbera o que Castilho (2006, p. 34) aponta: "[...] o aluno, durante o jogo, explora as situações a serem resolvidas com maior liberdade, e sem a pressão da avaliação, buscando a solução dos mesmos em um ambiente adequado à investigação e à busca”.

De acordo com Antunes (2003, p. 12), o professor é “[...] indispensável e imprescindível na aplicação de jogos", pois deve intervir na ação do jogo no momento em que ocorre algum erro, pois é exatamente quando o estudante tem a oportunidade de refletir sobre o assunto em questão, progredindo na sua formação (CUNHA, 2012).

Os jogos didáticos com finalidades pedagógicas revelam a sua importância, pois promovem situações de ensino e aprendizagem, além de propiciarem o aumento da construção do conhecimento, introduzindo atividades prazerosas, desenvolvendo a capacidade de iniciação, de ação ativa e motivadora (MOYLES, 2002).

No que se refere às Ciências da Natureza, o lúdico poderia contribuir ainda como forma de vencer a barreira da pretensa dificuldade e o hermetismo do conhecimento científico. Macedo (2008) sinaliza que atividades dessa ordem possibilitam aos estudantes estabelecer relações, testar hipóteses, criar possibilidades, analisar e intervir em resultados, expressar-se de modo construtivo e racional sem o ranço acadêmico de outras metodologias.

\section{PERCURSO METODOLÓGICO E DESENVOLVIMENTO DAS ATIVIDADES}

Esta pesquisa caracteriza-se como descritiva e qualitativa (GIL, 2002), pois foi desenvolvida em uma escola pública estadual de Ensino Médio e registra o envolvimento de estudantes com o componente curricular de Química, a partir da aplicação de um jogo didático.

Os sujeitos da pesquisa foram trinta e cinco (35) estudantes de duas turmas de terceira série do Ensino Médio. Do total de estudantes, três são provenientes da área rural do município de Dom Pedrito/ RS, os quais se deslocam de localidades rurais para estudarem em uma escola urbana.

A coleta de dados baseou-se na aplicação de um questionário respondido pelos alunos e, após a aplicação do jogo, que foi submetido à Análise de Conteúdo, objetivando perceber a manifestação das mensagens, o seu conteúdo e a sua expressão, foram avaliados de modo a evidenciar alguns indicadores para nortear a discussão do tema estudado (BARDIN, 2011; MINAYO, 2001).

A Análise de Conteúdo de Bardin (2011) consiste em: a) Pré-análise (fase de organização, sistematização das ideias na criação de um plano de análise); b) Exploração do material, pautada pela codificação (processo de transformação dos dados brutos, através de codificação ou enumeração destes); categorização (criação de categorias) e c) Tratamento dos resultados obtidos e interpretação (síntese e seleção dos resultados, validação e confronto do material com as dimensões teóricas).

$\mathrm{Na}$ etapa da pré-analise elaborou-se o questionário-piloto para sua posterior aplicação. $\mathrm{Na}$ exploração do material realizaram-se a leitura e a organização das respostas aos questionários, sistematizando as falas em possíveis categorias. Já a última etapa caracterizou-se pela discussão dos dados coletados a partir das categorias elencadas. 
$\mathrm{Na}$ construção metodológica, foram considerados todos os questionários. Após sua leitura e organização, os depoimentos contidos foram unitarizados e organizados a partir de categorias, proporcionando subsídios para a construção de textos descritivos, que foram interpretados com base no referencial teórico adotado. As categorias foram: Agrotóxicos e a Química; Aprendizagem com o jogo didático, as quais são discutidas a posteriori.

As unidades de análise correspondem às respostas dos estudantes ao questionário. Para organizar o conjunto das unidades, foi adotada a sistemática de grafá-las com a letra "E", referente ao estudante. Estes foram numerados de 1 a 35, sem que a numeração guardasse qualquer relação com o respondente. Essas unidades de análise e as respostas ao questionário aparecem grafadas em itálico no texto.

\section{Sequência Didática sobre agrotóxicos}

Para abordar a temática "agrotóxico", foi elaborada uma Sequência Didática relacionada à Química, em que se buscaram discutir os aspectos sociais, ambientais e econômicos que envolvem o tema.

A sequência didática foi estruturada em sete (07) momentos, sistematizados na Tabela 1; no último encontro foi proposta a aplicação de um jogo didático denominado "Trilha dos Agrotóxicos", com vistas a avaliar o que os estudantes aprenderam sobre o tema abordado e no qual foram focadas as discussões.

Tabela 1: Sistematização da Sequência didática aplicada

\begin{tabular}{|c|c|c|}
\hline Momento & Objetivo & Estratégias \\
\hline $\mathbf{0 1}$ & $\begin{array}{l}\text { Investigar o conhecimento dos alunos } \\
\text { frente ao tema agrotóxicos. }\end{array}$ & $\begin{array}{l}\text { Debates, partindo de um texto - "Veneno } \\
\text { nosso de cada dia"2. }\end{array}$ \\
\hline $\mathbf{0 2}$ & $\begin{array}{l}\text { Permitir a discussão com os alunos para } \\
\text { que se posicionem criticamente sobre o } \\
\text { uso de agrotóxicos e reconheçam a } \\
\text { química na agricultura. }\end{array}$ & Vídeos - "O veneno está na mesa II"3. \\
\hline 03 & $\begin{array}{l}\text { Apresentar o histórico sobre os } \\
\text { agrotóxicos, ressaltando o seu surgimento. }\end{array}$ & Vídeos. \\
\hline 04 e 05 & $\begin{array}{l}\text { Estudar a classificação, os tipos e a } \\
\text { toxicidade de agrotóxicos com o uso da } \\
\text { Química orgânica. }\end{array}$ & $\begin{array}{l}\text { Apresentação de algumas embalagens de } \\
\text { agrotóxicos e texto. }\end{array}$ \\
\hline 06 & $\begin{array}{l}\text { Mostrar aos estudantes como estamos nos } \\
\text { alimentando mal e perigosamente, } \\
\text { utilizando de forma errônea os } \\
\text { agrotóxicos. Resgatar o filme "Veneno } \\
\text { nosso de cada dia" como instrumento de } \\
\text { reflexão. }\end{array}$ & $\begin{array}{l}\text { Texto: “Agricultura sustentável: opção } \\
\text { inteligente”. }\end{array}$ \\
\hline $\mathbf{0 7}$ & $\begin{array}{l}\text { Avaliar a aplicação de um jogo } \\
\text { didático. }\end{array}$ & Jogo didático (Trilha). \\
\hline
\end{tabular}

Fonte: Autores

\section{O jogo didático “Trilha dos Agrotóxicos”}

O jogo foi adaptado do artigo de Silva et al. (2014), que objetivava propor um jogo didático na forma de tabuleiro sobre o tema fundamentos da ecologia, já que visava tornar as aulas de Biologia mais atrativas.

\footnotetext{
${ }^{2}$ Disponível em: https://goo.gl/k7PWew

3 Disponível em: https://goo.gl/egvPcA
} 
A elaboração do jogo foi no formato de "trilha", por proporcionar ao aluno participante o desafio de responder a perguntas e até mesmo questionar o seu adversário, além de possibilitar que o aluno reveja curiosidades sobre o tema de forma atraente e divertida. Assim, o jogo apresenta uma motivação, o aluno passa a ter um maior interesse pela atividade, uma vez que esta proporciona um aprendizado articulado entre teoria e prática.

A trilha foi pensada de maneira que abordasse os temas expostos durante a sequência didática; os problemas ambientais estão referenciados em algumas casas do tabuleiro, que tem suas cartas descritivas correspondentes para serem lidas pelos jogadores. No planejamento das cartas, e na tentativa de abordar a realidade vigente em relação à temática "agrotóxicos", buscamos dados e curiosidades ambientais atuais do Brasil.

Dessa forma, a trilha foi elaborada com a intenção de trabalhar os conceitos de revolução verde, semente crioula, controle biológico, produção orgânica, toxidade e nomenclatura das cadeias carbônicas, além de atentar sobre a questão do manuseio, da aplicação e da falta de proteção em relação aos agrotóxicos, além do descarte de embalagens e os agravos causados por estes à saúde e ao meio ambiente.

A trilha compreendia um tabuleiro de tamanho de $2 \mathrm{~m} \times 2 \mathrm{~m}$ impresso em lona (Figura 1) e possuía trinta e oito (38) casas, com cores e símbolos diferentes. A casa com sinal de exclamação, de cor verde, correspondia a "Responda". A que continha o sinal de interrogação, de cor amarela, a "Pergunte". A casa de cor azul, com os sinais de interrogação e exclamação, correspondia a "Curiosidades", e a casa com a imagem de uma "Caixa surpresa", era indicada pela cor laranja. Além disso, havia casas denominadas "Largada" e "Chegada”.

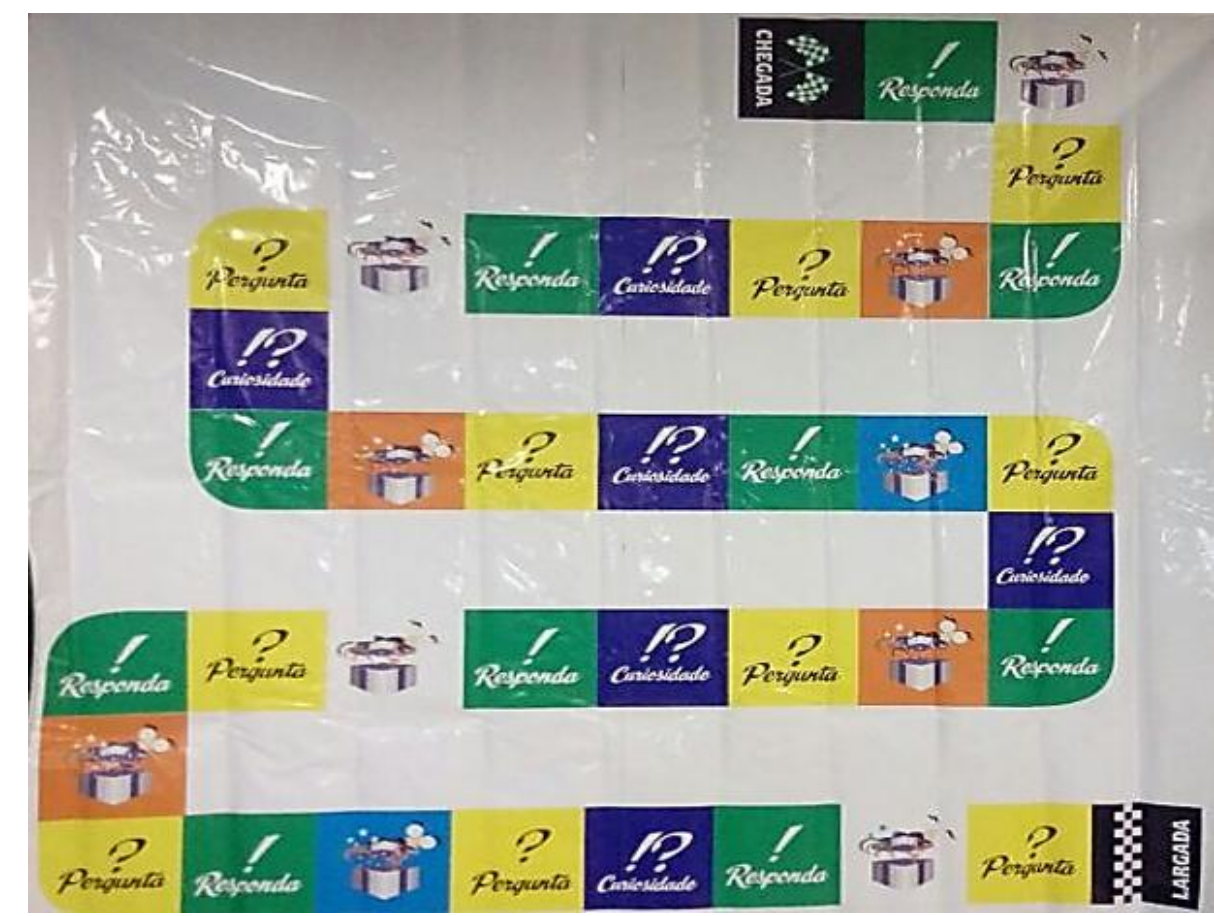

Figura 1: Jogo didático Trilha dos agrotóxicos. Fonte: Autores

O jogo possuía dez (10) cartas amarelas com perguntas, 10 cartas verdes com respostas, 10 cartas laranja com questões-surpresa, seis (o6) cartas azuis com curiosidades e um dado. O andamento do jogo ocorreu sempre com o lançamento do dado, que indicava quantas vezes o jogador deveria avançar. Se o jogador parasse na casa indicando a ação "Responda" (Quadro o1), deveria responder a uma pergunta; caso errasse, voltava uma casa. 
Quadro o1: Cartas Responda

\begin{tabular}{|c|c|c|c|c|}
\hline $\begin{array}{l}\text { Para que servem } \\
\text { os agrotóxicos? }\end{array}$ & $\begin{array}{c}\text { O que são } \\
\text { agrotóxicos? }\end{array}$ & $\begin{array}{c}\text { Para que é usado } \\
\text { o agrotóxico } \\
\text { glifosato? }\end{array}$ & $\begin{array}{c}\text { Você é produtor } \\
\text { de morangos e } \\
\text { não quer usar } \\
\text { agrotóxicos. } \\
\text { Quais são as } \\
\text { alternativas? }\end{array}$ & $\begin{array}{l}\text { Os agrotóxicos, } \\
\text { quando ingeridos } \\
\text { pelos seres vivos, } \\
\text { causam problemas } \\
\text { de saúde e até } \\
\text { mortalidade. Você } \\
\text { está de acordo } \\
\text { com esta citação? } \\
\text { Por quê? }\end{array}$ \\
\hline $\begin{array}{l}\text { O que são } \\
\text { rodízios de } \\
\text { culturas? }\end{array}$ & $\begin{array}{c}\text { Qual a } \\
\text { influência do } \\
\text { ser } \\
\text { dependente de } \\
\text { nove países } \\
\text { para manter } \\
\text { seu solo fértil? }\end{array}$ & $\begin{array}{l}\text { De que forma } \\
\text { podemos } \\
\text { minimizar os } \\
\text { efeitos dos } \\
\text { agrotóxicos? }\end{array}$ & $\begin{array}{l}\text { Cite alguns } \\
\text { impactos } \\
\text { ambientais da } \\
\text { utilização dos } \\
\text { agrotóxicos. }\end{array}$ & $\begin{array}{c}\text { Você está de } \\
\text { acordo com a } \\
\text { seguinte } \\
\text { exclamação: } \\
\text { “Menos amor, } \\
\text { mais Glifosato!”? } \\
\text { Por quê? }\end{array}$ \\
\hline
\end{tabular}

Fonte: Autores

Quando o jogador caísse em uma casa indicando a ação "Pergunte" (Quadro o2), deveria realizar uma pergunta para o grupo adversário; caso o escolhido acertasse, teria o direito de jogar o dado e poder avançar no jogo. Entretanto, se errasse a resposta, jogaria o dado indicando quantas casas retroceder.

Quadro o2: Cartas Pergunte

\begin{tabular}{|c|c|c|c|c|}
\hline $\begin{array}{l}\text { Que tipos de } \\
\text { desequilíbrio } \\
\text { ambiental pode } \\
\text { haver pelo mau } \\
\text { uso dos } \\
\text { agrotóxicos? }\end{array}$ & $\begin{array}{l}\text { O que poderia } \\
\text { ser feito para } \\
\text { amenizar a } \\
\text { utilização dos } \\
\text { agrotóxicos em } \\
\text { grande escala? }\end{array}$ & $\begin{array}{l}\text { A agricultura } \\
\text { químico- } \\
\text { industrial e o uso } \\
\text { de agrotóxicos } \\
\text { provocam } \\
\text { consequências } \\
\text { drásticas ao meio } \\
\text { ambiente. } \\
\text { Cite alguns destes: }\end{array}$ & $\begin{array}{l}\text { A evolução química } \\
\text { garantiu a } \\
\text { possibilidade de } \\
\text { produzir alimentos } \\
\text { suficientes para toda } \\
\text { a população do } \\
\text { planeta. Mesmo } \\
\text { assim, um problema } \\
\text { que ainda persiste éa } \\
\text { fome. Por que isso } \\
\text { acontece? }\end{array}$ & $\begin{array}{l}\text { Qual a } \\
\text { importância de } \\
\text { debater o tema } \\
\text { agrotóxico no } \\
\text { âmbito } \\
\text { escolar? }\end{array}$ \\
\hline $\begin{array}{l}\text { De que forma a } \\
\text { saúde humana } \\
\text { pode ser afetada } \\
\text { pelo uso dos } \\
\text { agrotóxicos? }\end{array}$ & $\begin{array}{l}\text { Cite vantagens } \\
\text { da utilização dos } \\
\text { agrotóxicos: }\end{array}$ & $\begin{array}{l}\text { Qual a ligação } \\
\text { entre a Química e } \\
\text { os agrotóxicos? }\end{array}$ & $\begin{array}{l}\text { O que é controle } \\
\text { biológico? }\end{array}$ & $\begin{array}{l}\text { Qual a função } \\
\text { da ANVISA em } \\
\text { relação aos } \\
\text { agrotóxicos? }\end{array}$ \\
\hline
\end{tabular}

Fonte: Autores

Quando o jogador caísse em uma casa indicando a ação "Surpresa" (Quadro o3), deveria ler uma carta retirada do monte que continha informações sobre agrotóxicos, revolução verde e semente crioulas; além disso, continha informações sobre o número de casas que deveriam avançar ou retroceder. 
Quadro o3: Carta Surpresa

\begin{tabular}{|c|c|c|c|c|}
\hline $\begin{array}{c}\text { Polícia } \\
\text { Rodoviária } \\
\text { Federal flagra } \\
\text { transporte de } \\
\text { agrotóxicos } \\
\text { contrabandeados. } \\
\text { Volte } 3 \text { casas. }\end{array}$ & $\begin{array}{l}\text { Os EPI's foram } \\
\text { usados antes da } \\
\text { aplicação dos } \\
\text { agrotóxicos! } \\
\text { Avance } 1 \text { casa. }\end{array}$ & $\begin{array}{c}\text { Todas as } \\
\text { embalagens } \\
\text { vazias de } \\
\text { agrotóxicos } \\
\text { foram devolvidas } \\
\text { ao local indicado } \\
\text { na nota fiscal. } \\
\text { Avance } 2 \text { casas. }\end{array}$ & $\begin{array}{c}\text { Foi detectada } \\
\text { doença em } \\
\text { agricultor por } \\
\text { intoxicação por } \\
\text { organofosforados } \\
\text { no exame de } \\
\text { sangue! } \\
\text { Volte } 2 \text { casas. }\end{array}$ & $\begin{array}{c}\text { Foram } \\
\text { multiplicadas as } \\
\text { sementes crioulas } \\
\text { com a intenção de } \\
\text { fortalecer os } \\
\text { bancos de } \\
\text { sementes } \\
\text { comunitários. } \\
\text { Avance } 3 \text { casas. }\end{array}$ \\
\hline $\begin{array}{l}\text { Você aproveitou } \\
\text { a visita do } \\
\text { agrônomo para } \\
\text { tirar dúvidas } \\
\text { sobre que tipo de } \\
\text { controle de } \\
\text { pragas você pode } \\
\text { usar. } \\
\text { Avance } 2 \text { casas. }\end{array}$ & $\begin{array}{c}\text { Foram } \\
\text { encontradas } \\
\text { embalagens de } \\
\text { agrotóxicos nas } \\
\text { proximidades } \\
\text { do rio. } \\
\text { Volte à largada. }\end{array}$ & $\begin{array}{c}\text { Por que é } \\
\text { importante o } \\
\text { cultivo de } \\
\text { alimentos } \\
\text { orgânicos? } \\
\text { Caso esteja } \\
\text { correto, } \\
\text { Avance } 3 \text { casas } \\
\text { Senão } \\
\text { permaneça no } \\
\text { mesmo lugar! }\end{array}$ & $\begin{array}{l}\text { Foi detectado na } \\
\text { região um } \\
\text { desequilíbrio } \\
\text { ambiental por } \\
\text { uso inadequado } \\
\text { de agrotóxicos. } \\
\text { Volte } 3 \text { casas. }\end{array}$ & $\begin{array}{c}\text { Mau uso dos } \\
\text { agrotóxicos viola } \\
\text { as leis que regulam } \\
\text { as regras de } \\
\text { condutas e coloca } \\
\text { em perigo as } \\
\text { pessoas ou o meio } \\
\text { ambiente. Foram } \\
\text { identificadas } \\
\text { alterações e } \\
\text { remoção de } \\
\text { rótulos nos } \\
\text { agrotóxicos. } \\
\text { Volte } 1 \text { casa. }\end{array}$ \\
\hline
\end{tabular}

Fonte: Autores

Quanto às casas "Curiosidades" (Quadro 04), abordavam informações sobre os agrotóxicos, revolução verde e semente crioula. Ganhava o jogo quem primeiro chegasse à casa identificada pela palavra "Chegada".

Quadro o4: Cartas Curiosidade.

\begin{tabular}{|c|c|c|}
\hline Você sabia? & Você sabia? & Você sabia? \\
\hline $\begin{array}{l}\text { Os agrotóxicos, quando } \\
\text { ingeridos pelos seres vivos, } \\
\text { causam problemas de saúde e } \\
\text { até mortalidade. }\end{array}$ & $\begin{array}{l}\text { Que, ao atingirem os órgãos, os } \\
\text { agrotóxicos podem causar } \\
\text { alterações nos sistemas do corpo } \\
\text { humano. } \\
\text { Sabe de algum caso? }\end{array}$ & $\begin{array}{c}\text { Que a Revolução Verde se } \\
\text { refere a invenções e } \\
\text { disseminações de novas } \\
\text { sementes e práticas agrícolas. } \\
\text { Refere-se a sementes } \\
\text { geneticamente modificadas e o } \\
\text { uso desenfreado de fertilizantes } \\
\text { e agrotóxicos. }\end{array}$ \\
\hline Você sabia? & Você sabia? & Você sabia? \\
\hline $\begin{array}{l}\text { Alguns estudos apontam alto } \\
\text { índice de suicídios e o uso de } \\
\text { agrotóxicos em trabalhadores } \\
\text { rurais, devido ao acúmulo } \\
\text { dessas substâncias no sistema } \\
\text { endócrino e nervoso. } \\
\text { Você já leu algo sobre isso na } \\
\text { região? }\end{array}$ & $\begin{array}{l}\text { Que a revolução verde teve início } \\
\text { em 1940 e os resultados } \\
\text { expressivos foram na década de } \\
\text { 1960 e 1970, quando os países em } \\
\text { desenvolvimento aumentaram } \\
\text { significativamente a produção } \\
\text { agrícola. }\end{array}$ & $\begin{array}{l}\text { Que as sementes crioulas são } \\
\text { sementes tradicionais, } \\
\text { mantidas e selecionadas por } \\
\text { várias décadas através da } \\
\text { agricultura familiar. }\end{array}$ \\
\hline
\end{tabular}

Fonte: Autores 
O jogo aqui apresentado foi elaborado visando a uma proposta de trabalho diferenciada para alunos de Ensino Médio. Entretanto, este pode ser adaptado a diferentes realidades e a outros níveis de ensino, sem perder o caráter lúdico e educativo.

\section{RESULTADOS E DISCUSSÕES}

As unidades de análise referentes ao questionário possibilitaram identificar as seguintes categorias: Agrotóxicos e a Química; Aprendizagem com o jogo didático, e são discutidas a seguir.

\section{Agrotóxicos e a Química}

Observou-se que a aplicação do jogo didático foi significativa, pois houve novos questionamentos e diálogos por parte dos alunos em relação ao tema apresentado. Quando perguntados sobre a compreensão em relação à nomenclatura das cadeias carbônicas e Agrotóxicos, a aplicação do jogo didático parece ter sido favorável, pelas respostas de alguns estudantes, como de E1 e E3, respectivamente: "Sim, porque é uma atividade que ajuda o aluno a compreender mais sobre os agrotóxicos e a química orgânica, podendo assim saber seus males e bens para a saúde, etc.". "Sim. Aprendi várias coisas que não estavam no meu conhecimento".

Os discentes E10 e E15, respectivamente, consideraram o jogo didático como uma atividade que contribuiu ao aprendizado, favorecendo tanto a compreensão do conteúdo da Química como da temática agrotóxicos, a saber: "Sim, pois com as atividades deu para reconhecer os prós e contras que um agrotóxico pode causar" e "Sim, pois tinha muitas situações que eu não conhecia e produtos."

Para Prass (2012), o sujeito é interativo, pois adquire o conhecimento a partir das relações e de troca com o meio, por intermédio de um processo denominado mediação. Sendo assim, uma maneira de promover a interação e a troca de conhecimentos entre os alunos é a formação de grupos colaborativos, que são estruturados contemplando alunos de diferentes níveis de conhecimento, como se percebe na fala do E23: "Com certeza, tivemos várias ideias trocadas, e de E31: "Sim, pude esclarecer várias dúvidas."

\section{Aprendizagem com o Jogo didático}

Percebeu-se que o jogo didático tornou significativa a aprendizagem dos estudantes, pois abordou uma estratégia didática que auxiliou no trabalhar de forma contextualizada na questão dos Agrotóxicos, relacionando-se ao cotidiano e articulando-se aos conceitos da Química. Pode-se identificar, pelas afirmações dos estudantes:

E2: "Sim, porque alguns assuntos que eu não tinha muito entendimento ficaram mais claros."

E6: "Sim, a turma em geral se interessa mais quando tem aula assim."

E11: "Foi um modo divertido e descontraído de aprender, despertou o interesse de responder e procurar entender."

E18: Sim, pois, além de divertir os alunos, acabou ajudando todos a entender a matéria."

De acordo com Cabrera (2007), com base na aplicação dessas estratégias para os alunos do Ensino Médio, a aprendizagem ocorre de maneira natural e espontânea, pois, ao jogar, o adolescente transpõe a experiência para o campo da aprendizagem, com interesse, prazer e alegria, conforme se pode perceber nas falas dos estudantes.

E15: "Sim, pois foi muito boa e ajuda o desenvolvimento e conhecer os assuntos." 
E21: "Sim, porque é bom ter aulas diferentes e a gente aprende mais."

Cabrera (2007) defende que utilizar jogos para fins didáticos é importante, pois o clima descontraído e motivador favorece o estabelecimento de relações interpessoais e, consequentemente, um ambiente adequado para a aprendizagem na busca de resultados positivos, como menciona E3: "Sim, pois é uma forma mais fácil de aprender o conteúdo, e também melhorar a convivência com os outros alunos."

Quando questionados se gostariam de estudar outros conteúdos com atividades semelhantes a que fora aplicada, todos manifestaram interesse em estudar utilizando-se de outros tipos de estratégia. Além disso, expressaram que foram capazes de debater em grupo e expor suas opiniões.

Vale ressaltar que alguns alunos possuem dificuldades de relacionamento, por timidez ou por não terem facilidade de entrosamento e, assim, o jogo proporcionou um diálogo entre os estudantes da turma.

Os alunos foram questionados se sentiram alguma dificuldade durante o desenvolvimento do jogo didático, para que se pudesse refletir em que aspecto poder-se-ia melhorar a abordagem das atividades. Dos 35 questionários analisados, vinte e quatro (24) estudantes disseram que não tiveram dificuldades durante a atividade e, quando esta aparecia, puderam "tirá-la" com colegas e com a professora. Nove (og) responderam que tiveram algumas dúvidas em relação a algumas perguntas, como se observa, a seguir:

E11: "Algumas coisas eu não lembrava, mas foram bem esclarecedoras as explicações da professora."

E15: "Mais ou menos, com alguns agrotóxicos, seus nomes e funções."

E26: "Sim, porque eu não tinha conhecimento avançado sobre o tema."

E28: “Um pouco, pois havia perguntas que eu não sabia responder."

Vinte e oito (28) estudantes mencionaram que o jogo fora bem elaborado e que poderiam ser realizadas práticas como essas mais vezes durante as aulas, por ser um modo atraente e diversificado de estudar, a saber:

E3: "Ele foi bem desenvolvido e nos concedeu mais conhecimento."

E1o: "O jogo foi bem legal e conseguimos aprender a jogar em grupos e aprender bastante sobre o conteúdo."

E11: "Acho que foi dinâmico, fácil e interessante, sem nenhuma sugestão. Foi bem executado."

E17: “Todos se divertiram e aprenderam muitas coisas novas."

Zanon et al. (2008), em seu estudo, revelam que, após a aplicação de um jogo didático, os alunos destacaram que se sentiram mais motivados e ativos. Os autores afirmam ainda que o jogo foi um fator de estímulo, entusiasmando mesmo aqueles que só observaram, aguçando a curiosidade. Diante do exposto, percebeu-se que o jogo foi capaz de despertar o interesse e a atenção dos estudantes de forma a contribuir com o seu aprendizado, tornando as aulas mais instigantes.

\section{CONSIDERAÇÕES FINAIS}

Esta pesquisa, que buscou investigar as potencialidades e limitações em relação à aplicação de um jogo didático sobre a temática agrotóxicos, contribuiu para um aprendizado mais significado dos 
estudantes envolvidos, da mesma forma que auxiliou na articulação teórico-prática de estratégias contextualizadas para o Ensino de Química.

Como limites na aplicação do jogo didático, destacamos a organização curricular e o tempo limitado para aplicar e explorar melhor a aplicação da atividade. O tempo gasto com as tarefas do jogo em sala de aula é maior e, se o professor não estiver preparado, pode existir um sacrifício de outros conteúdos pela falta de tempo. As desvantagens podem ocorrer pela inabilidade e planejamento frágil do professor que, no anseio de atingir os objetivos pensados, interfere de maneira inadequada durante a execução dos jogos.

Aponta-se para a relevância de estratégias didáticas contextualizadas que ultrapassem as abordagens isoladas de conceitos, de modo que possibilitem realizar relações com outras áreas de conhecimento e/ou de questões práticas do cotidiano. Nascimento, Ricarte e Ribeiro (2007) mencionam que se deve trabalhar de maneira dinâmica e contextualizada, pois é de fundamental importância repensar as abordagens tradicionais de ensino, a fim de serem superadas por diferentes estratégias, e a partir das quais os alunos possam ser sujeitos ativos da aprendizagem.

Dessa forma, acredita-se que o planejamento e a aplicação de estratégias, bem como a reflexão em torno delas, auxiliam os processos de aprendizagem, favorecendo a motivação interna, a argumentação e a interação entre alunos e professores, possibilitando que o aluno possa vivenciar e contextualizar o seu dia a dia através de conceitos da Química.

\section{REFERÊNCIAS}

ANTUNES, C. Jogos para a estimulação das múltiplas inteligências. 12. ed. Rio de Janeiro: Vozes, 2003.

BARDIN, L. Análise de conteúdo. Lisboa: Edições 7o, 2011.

BRASIL. Secretaria de Educação Fundamental. Parâmetros Curriculares Nacionais: ciências naturais. Brasília, 1997. Disponível em: <http://portal.mec.gov.br/seb/arquivos/pdf/ciencias.pdf> Acesso em: 14 out. 2017.

. Ministério da Educação. Secretaria de Educação Básica. Orientações Curriculares para o Ensino

Médio: Ciências da natureza, matemática e suas tecnologias. Brasília: MEC/SEB, 2006.

. Ministério da Educação. Diretrizes Curriculares Nacionais Gerais para a Educação Básica. Resolução CNE/CEB no 4/2010.

BRAIBANTE, M. E. F.; ZAPPE, J. A. A Química dos Agrotóxicos. Química Nova na Escola, v. 34, n. 1, p. 10-15, 2012.

CABRERA, W. B. A ludicidade para o ensino médio na disciplina de Biologia: contribuições ao processo de aprendizagem em conformidade com os pressupostos teóricos da aprendizagem significativa. Dissertação. Mestrado em Ensino de Ciências e Educação Matemática. Universidade Estadual de Londrina Paraná, 2007.

CAMPOS, L. M. L.; BORTOLOTO, T. M.; FELICIO, A. K. C. A produção de jogos didáticos para o ensino de Ciências e Biologia: uma proposta para favorecer a aprendizagem. Caderno dos Núcleos de Ensino, p. 35-48, 2003.

CASTILHOS, D. R. B. A afetividade e o lúdico na aprendizagem. São Paulo: UNICAMP, 2006.

CAVALCANTI, J. A. Agrotóxicos: uma temática para o ensino de Química. Química Nova na Escola. São Paulo, v. 32, n. 1, p. 31-36, fev. 2010.

CHASSOT, A. I. A educação no ensino de química. Ijuí: Unijuí, 1990. 
CUNHA, M. Jogos no Ensino de Química: considerações teóricas para sua utilização em sala de aula. Santa Maria: Química Nova na Escola, v. 34, n. 2, 2012.

DELIZOICOV, D.; ANGOTTI, J. A.; PERNAMBUCO, M. M. Ensino de ciências: fundamentos e métodos. São Paulo: Cortez, 2011.

DOM PEDRITO. Assembleia legislativa do estado do Rio Grande do Sul. Comissão de saúde e meio ambiente. ATA 24/2016. Dom Pedrito/RS, 2016.

FERREIRA, Z. R. S. O ensino de Ciências Naturais e sua importância. Webartigos. 2013. Disponível em: $<$ https://www.webartigos.com/artigos/o-ensino-de-ciencias-naturais-e-sua-importancia/116403>. Acesso em: 07 nov. 2017.

FONSECA, E. M; DUSO, L.; HOFFMANN, M. B. Discutindo a temática agrotóxicos: uma abordagem por meio das controvérsias científicas. Rev. Bras. Educ. Camp., Tocantinópolis, v. 2, n. 3, p. 881-897, 2017.

FORTUNA, T. R. Jogo em aula. Revista do Professor, Porto Alegre, v. 19, n. 75, p. 15-19, jul./set. 2003.

GIL, A. C. Como elaborar projetos de pesquisa. São Paulo: Atlas, 2002.

KISHIMOTO, T. M. Jogo, brinquedo, brincadeira e a educação. São Paulo: Cortez, 1996.

MACEDO, L. Os jogos e sua importância na escola. Cadernos de Pesquisa, São Paulo, n. 93, p. 5-11, 1995.

MINAYO, Maria Cecília de Souza (Org.). Pesquisa Social: Teoria, método e criatividade. 18. ed. Petrópolis: Vozes, 2001.

MOYLES, J. R. Só brincar? O papel do brincar na educação infantil. Tradução: Maria Adriana Veronese. Porto Alegre: Artmed, 2002.

NASCIMENTO, T. L.; RICARTE, M. C. C.; RIBEIRO, S. M. S. Repensando o Ensino de Química Orgânica à Nível Médio. In: 47 ${ }^{\circ}$ Congresso Brasileiro de Química, 2007, Natal. Anais do $47^{\circ}$ Congresso Brasileiro de Química, Natal, 2007.

PRASS, A. R. Teorias de Aprendizagem. 2017. Disponível em:

$<$ http://www.fisica.net/monografias/Teorias de Aprendizagem.pdf >. Acesso em: 21 nov. 2017.

PEDROZO, C.V. Jogos didáticos no ensino de biologia: uma proposta metodológica baseada em módulo didático. Anais do IX Congresso Nacional de Educação. EDUCERE. II Encontro Sul Brasileiro de Psicopedagogia. 26-29 de outubro de 2009. PUCPR. p. 3183. [Online]. Acesso em: 12 ago. 2010.

SANTOS, W. L. P.; MORTIMER, E. F. Uma análise de pressupostos teóricos da Abordagem C-T-S (CiênciaTecnologia-Sociedade) no contexto da Educação Brasileira. Revista Ensaio, v. 2, n. 2, p. 1-23, 2002.

SILVA, E. L. Contextualização no ensino de química: ideias e proposições de um grupo de professores. Dissertação. São Paulo 2007. Disponível em:

$<$ http://www.educadores.diaadia.pr.gov.br/arquivos/File/marc02012/quimica artigos/contex ens quim disser t.pdf >. Acesso em: 19 nov. 2017.

SILVA, N. C. M.; FERNANDES, S. M.; MENDES, C. C. M.; DANTAS; S. M. M. M. Proposta de um jogo de tabuleiro sobre o tema fundamentos da ecologia para ensino médio. Revista da SBENBIO, n. 7, 2014.

SILVEIRA, R. S.; BARONE, D. A. C. Jogos Educativos computadorizados utilizando abordagem de algoritmos genéticos. Universidade Federal do Rio Grande do Sul. Instituto de Informática. Curso de PósGraduação em Ciências da Computação. 1998.

SOARES, M.; OKUMURA, F.; CAVALHEIRO, E. Proposta de um jogo didático para ensino do conceito de equilíbrio químico. Química Nova na Escola, 2003. 
ZANON, D. A. V.; GEUERREIRO, M. A. S.; OLIVEIRA, R. de. Jogo didático ludo químico para o ensino de nomenclaturas dos compostos orgânicos: projeto, produção, aplicação e avaliação. Departamento de didática, UNESP - SP, 2008.

Laura Freire Mello: Graduada em Ciências Biológicas pela Universidade da Região da Campanha. Docente do Colégio Estadual Candida Corina Taborda Alves e na Escola Estadual de Ensino Fundamental Coronel Urbano das Chagas. Supervisora do PIBID de 2014 até 2016, projeto Ciências da Natureza - UNIPAMPA Dom Pedrito.

E-mail: laurafreirebio@hotmail.com

Eril Medeiros da Fonseca: Licenciado em Ciências da Natureza pela Universidade Federal do Pampacampus Dom Pedrito. Especialização em Ensino de Ciências na Educação do Campo e Mestrando em Ensino no Programa de Pós-Graduação em Ensino pela Universidade Federal do Pampa- campus Bagé.

E-mail: erilmf@gmail.com

Leandro Duso: Professor adjunto da Universidade Federal do Pampa (UNIPAMPA), Campus Dom Pedrito. Doutor em Educação Cientifica e Tecnológica pela Universidade Federal de Santa Catarina - UFSC. Mestre em Ensino de Ciências e Matemática pela Pontifícia Universidade Católica do Rio Grande do Sul - PUCRS. Licenciado e Bacharel em Ciências Biológicas pela Universidade de Caxias do Sul. Diretor da Associação Brasileira de Ensino de Biologia (SBENBIO) regional 3. Tem experiência na área de Ensino de Ciências e Biologia, com ênfase em Educação Científica e Tecnológica, atuando principalmente nos seguintes temas: ensino de ciência, metodologia de ensino, abordagem CTS e formação de professores.

E-mail:dusoleandro@gmail.com 